\title{
Correction to: Cell Senescence in Lupus
}

\section{Lin Gao $^{1} \cdot$ Maria Slack ${ }^{1} \cdot$ Jennifer L. Barnas ${ }^{1} \cdot$ Andrew McDavid $^{2} \cdot$ Jennifer Anolik ${ }^{1} \cdot$ R. John Looney ${ }^{1}$}

Published online: 23 May 2019

(C) Springer Science+Business Media, LLC, part of Springer Nature 2019

\section{Correction to: Current Rheumatology Reports (2019) 21: 1 https://doi.org/10.1007/s11926-019-0800-6}

The original version of this article unfortunately contained mistakes.

(1) Jennifer L. Barnas was not listed among the authors. The author group is corrected as shown above.

(2) There is an error in Figure 1: The "INF $\beta$ " should be "IFN $\beta$ ". The corrected figure is given below.

Fig. 1 Cellular senescence

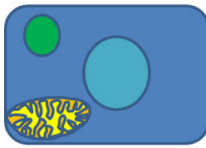

Lysosomes

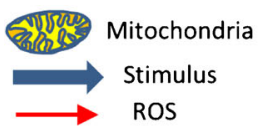

$\longrightarrow$ ROS

$\longrightarrow$ CGAMP IRF3, NFKB

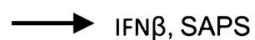

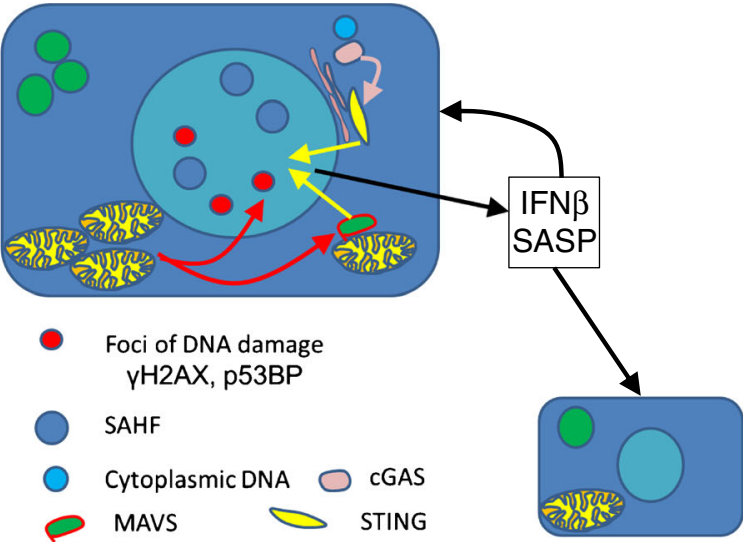

Endoplasmic reticulum

Publisher's Note Springer Nature remains neutral with regard to jurisdictional claims in published maps and institutional affiliations.

The online version of the original article can be found at https://doi.org/ 10.1007/s11926-019-0800-6

R. John Looney

John_Looney@urmc.rochester.edu

1 Allergy Immunology Rheumatology Division, Department of Medicine, University of Rochester School of Medicine and Dentistry, Rochester, NY, USA

2 Department of Biostatistics and Computational Biology, University of Rochester School of Medicine and Dentistry, Rochester, NY, USA 